\title{
Creating Equitable Learning Environments in Architectural Studio Courses
}

\author{
EVAN PRUITT \\ DAVID KRATZER \\ Thomas Jefferson University \\ Thomas Jefferson University
}

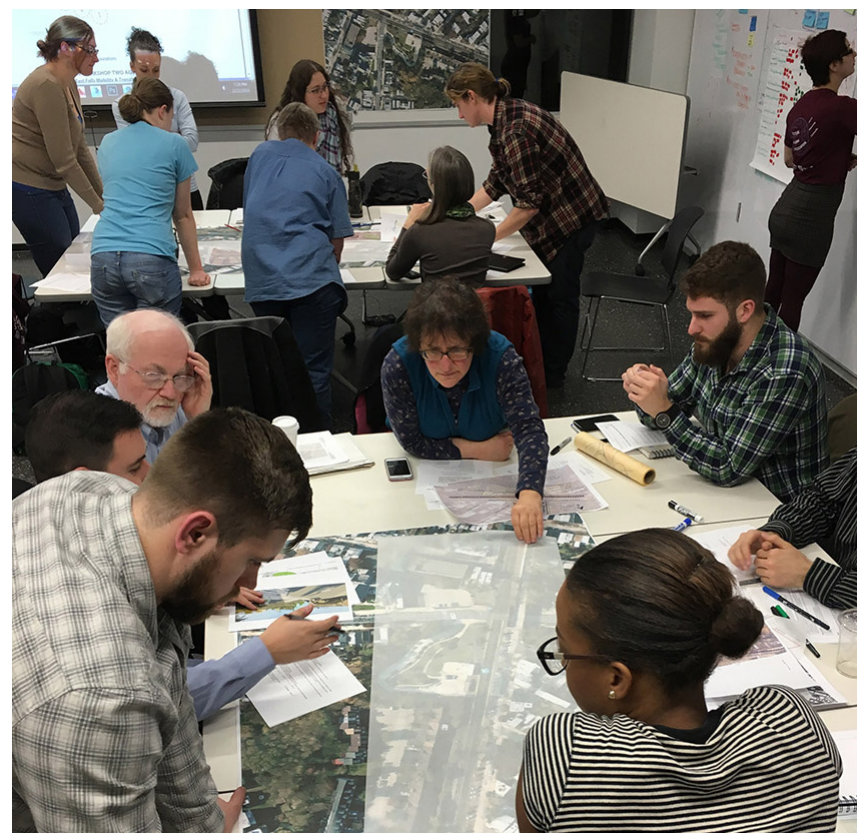

Figure 1: Design Charette. Jefferson (source: authors).

This paper explores the relationship between student temperament, curriculum and learning environments in architectural studio courses. If we can acknowledge that students with different temperaments are effected by different curriculum models and spatial environments, the concluding proposition is that professors might better tailor studio design courses to be more inclusive of all learning preferences.

The best learning results from a particular kind of social interaction: when teachers, students, and community members work together in a situated activity to construct shared understanding. Learners develop understandings of principles and ideas through sharing, using and debating ideas with others. ${ }^{1}$

- Krajcik \& Blumenthal; "Project Based Learning."

\section{THE PUBLIC STUDIO}

The studio environment in architectural education harnessed the techniques of "project-based learning" long before it became a defined academic approach for teaching the complexities of real-world problems. Open floor plans, fluid rows of working surfaces, communal discussions, group design projects and public reviews are just a few of the defining elements of a traditional studio environment. In this sense, the pedagogical approach and spatial environment of a traditional architectural studio course are intrinsically linked in an effort to promote an interactive process which is open, active and public.

Although extroverted, "ambiverted" and introverted temperamental tendencies are in a constant state of flux, it can be hypothesized that current project-based learning pedagogies and the environments within which they are implemented cater to students and faculty with extroverted tendencies. In years past, however, architecture students who identified as introverts were encouraged to construct their own learning lairs within the studio, limiting their public participation to formal reviews. Group projects were also less common, allowing introverts to remain shielded from open, active and public dialogs. The increased push towards interdisciplinary group based learning in addition to mandated open floor plans have diminished the opportunity to simultaneously exist within a studio environment while maintaining personal boundaries. As a result, introverted students are forced into a milieu that might inflict personal discomfort and academic hesitation. Should the traditional studio model remain in strict form, it is possible students with great aptitude may choose to study another discipline as a result of a mismatch between their temperament and the learning environment promoted in architectural education.

This short paper explores the dilemma of students with introverted tendencies operating in more extroverted "project based learning" systems and their corresponding environments. The paper concludes by proposing a studio structure that promotes equitable learning environments for students of all temperaments and learning preferences. Findings from a "first run" summer studio that examined student engagement, participation and productivity under varied pedagogical and spatial environments will be offered.

\section{EXTROVERSION + DESIGN THINKING}

Tim Brown, in his book Change by Design: How Design Thinking Transforms Organizations and Inspires Innovation argues for use of a creative problem solving approach called "design thinking" as a platform for innovation in "business and society as a whole." ${ }^{\prime 2}$ By appropriating the skills of designers to integrate "what is desirable from a human point of view with what is technologically feasible and economically viable," collaborative teams can uniquely address "a vastly 
greater range of problems" leading to rich, innovative and forward thinking work. Design thinking methods shift collective thinking from "a solitary problem" to "a project," which becomes a vehicle for exploration, research, prototyping and development of wider creative propositions. The project is a closed loop system with a clear beginning and end forcing concentrated focus on the issues at hand. Central to Brown's platform is the project team, where creative exploration occurs through interaction between a varied set of skilled individuals.

Within academia, "design thinking" is akin to "project based learning" pedagogies where, as a foundational curricular component, projects are "relatively long-term, problemfocused, and meaningful units of instruction that integrate concepts from a number of disciplines or fields of study." ${ }^{3}$ At the core is the "problem," which in order to be effective must be authentic, interesting, research-based, relevant and have a clear rationale in order for positive engagement by learners. ${ }^{4}$ To be successful, the projects must be well formed such that students take ownership of the problems - not to simply mimic a practitioner, but rather to "learn about a field by thinking like a member of that practice community."

Where the projects involve the creation of artifacts, as in architectural education, project based learning can become the literal construction of the knowledge gained - "artifacts are the representations of the student's problem solution that reflect emergent states of knowledge." ${ }^{16}$ For Richard Sennett, this process of artifact "making" promotes skill development, which our current "modern world skills economy" does not favor but desperately needs to generate critical thinking skills. ${ }^{7}$ Borrowing from Diderot, he states, "as we get better at problem solving we ought to also get better at problem finding, so every solution should open up a new problem."

If we are to accept the proposition that our educational system focuses on preparing students for the future, then project based learning methodologies surely prefigure Brown's corporate design thinking model. It is important to note that project based learning is inherently social and based in community relations. The current educational emphasis on collaboration, especially interdisciplinary collaboration, assembles students into project based teams where not only is the subject matter explored through projects and problem solving, but students must also learn the nuances of teamwork and professional compromise. For many, learning occurs primarily in a social context where "learners interact with and internalize modes of knowing and thinking represented and practiced in a community. ${ }^{18}$ Such social collaborative teamwork, especially in architectural education, relies on an interactive process that is active and, by nature, public - deliberations occur quickly and in the open amongst teammates, clients, stakeholders, students, professionals, and other constituents. Brainstorming, design workshops, and charettes become the primary tools for codifying this interaction and one's ability to successfully operate in these settings is often the foundation of their eventual evaluation.

At the risk of over-generalizing, extroverts tend to stand out in these educational and professional settings, making their successes easier to assess and, ultimately, promote. Persons with introversion tendencies, though, tend to be at a distinct disadvantage. Is the educational studio ethical if not all students can comfortably participate?

\section{INTROVERSION + THE ETHICAL DILEMMA}

"The same person who would never raise his hand in a lecture hall of two hundred people might blog to two thousand, or two million, without thinking twice. The same person who finds it difficult to introduce himself to strangers might establish a presence online and then extend these relationships into the real world." ${ }^{\prime 9}$

\section{- Susan Cain, Quiet: The Power of Introverts in a World That Can't Stop Talking}

Susan Cain, an author and educator, posits that "introverts are too often undervalued within our current educational and professional system." Shyness is a social anxiety disorder while introversion is a biologically based temperament..$^{10}$ This is an important distinction. Introverts process information and respond to stimulation differently, making them uncomfortable with quick "public" thinking and open interaction. Our "extrovert-dominated" society minimizes the uniquely creative capabilities of more introverted persons leading to "a colossal waste of talent, energy and happiness."

The incorporation of design thinking and project based learning within professional settings and academia has no doubt changed both the interactions between collaborators and the physical space that houses these interactions.

Simply because extroverts illuminate their thoughts and processes with greater ease, this does not mean that introverts are less capable of making significant contributions to the same objectives. They are often just overshadowed. With fields outside of traditionally defined "design" professions looking more and more to adopt principals of design thinking and project based learning, work process, institutional culture, evaluations and promotions will naturally trend towards rewarding extroverted tendencies. As a result, the introvert will not have the same opportunities to succeed, which must be addressed as an ethical dilemma.

How can we balance the power of Tim Brown's "design thinking" and Susan Cain's desire for inclusive environments, such that the capacity for introverts to contribute is not diminished? 


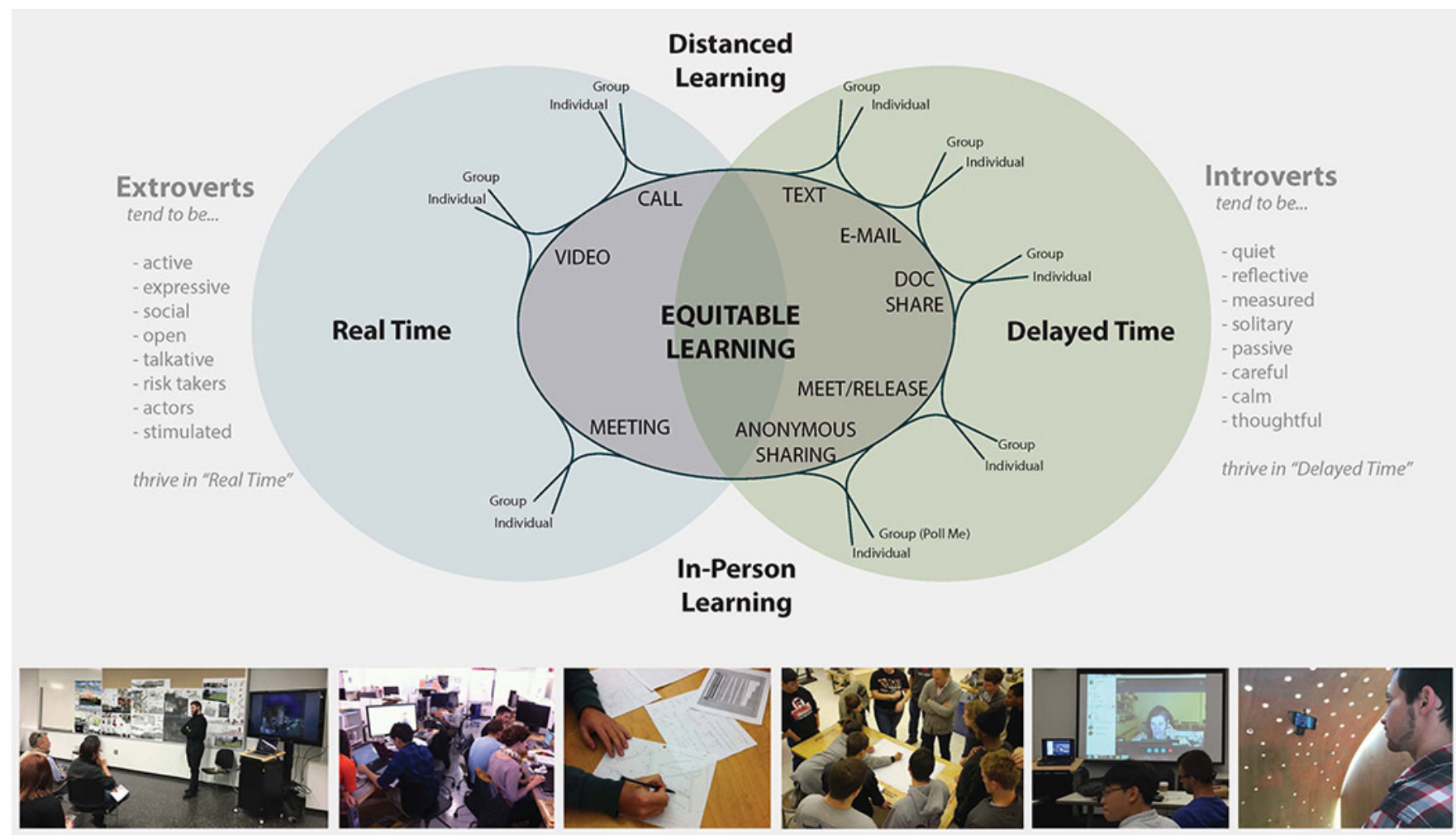

Figure 2: Equitable Studio Matrix (source: authors).

\section{EQUITABLE LEARNING IN ARCHITECTURAL EDUCATION}

Current design studios are often based on the foundation of "active, collaborative, and real-world learning" ${ }^{10}$ - all of which are closely aligned with the core tenants of design thinking and project-based learning. These forms of open learning have also been the cornerstone of a traditional architectural studio design course. Years of teaching experience in architectural studio courses have illuminated that not all students are comfortable participating in a public, active, collaborative setting. Instead, some students establish their working station away from their peers and sit in the back during group brainstorming sessions. They often do not ask questions at one-on-one desk critiques with professors and struggle to verbally present their work in front of invited jurors. The design work these students produce, however, is often powerful and ripe with potential - meaning that they cannot be accurately categorized as "disengaged."

It is important to recognize that there is not one teaching mechanism that has the capacity to reach all students. Designing courses to have varied pedagogies and environments that optimally reach as many students as possible is a challenging undertaking, even for the most seasoned professor. Could the structure of a studio be adjusted, though, to inspire greater engagement, participation and productivity for those students who are not inherently comfortable in open, active and public learning environments? The results of such an experiment might provide insight into teaching different temperaments within any course or discipline that has adopted design thinking or project based learning principals.

\section{DESIGNING AN EQUITABLE ARCHITECTURE STUDIO COURSE}

In the Summer of 2017, we developed and deployed a test course for an introductory architectural design studio with the goal of creating a more equitable learning environment for students with varied temperaments. During the studio sessions and afterword through surveys, data was gathered to determine the effectiveness of the course adjustments.

\section{Studio Goals}

The goals for the course were established as follows:

- Identify if students with a variety of temperaments can be equally engaged in a dynamic learning environment, such as an architectural studio course.

- To develop evaluation techniques that are equitable to all temperaments.

- To learn the virtual communication software ZOOM and utilize it to teach on-line architectural studio sessions.

\section{Studio Metrics}

The course was designed to consider three primary metrics: pedagogy, space and evaluation.

Pedagogically, the course presented varied project structures to include both individual and group oriented work. 


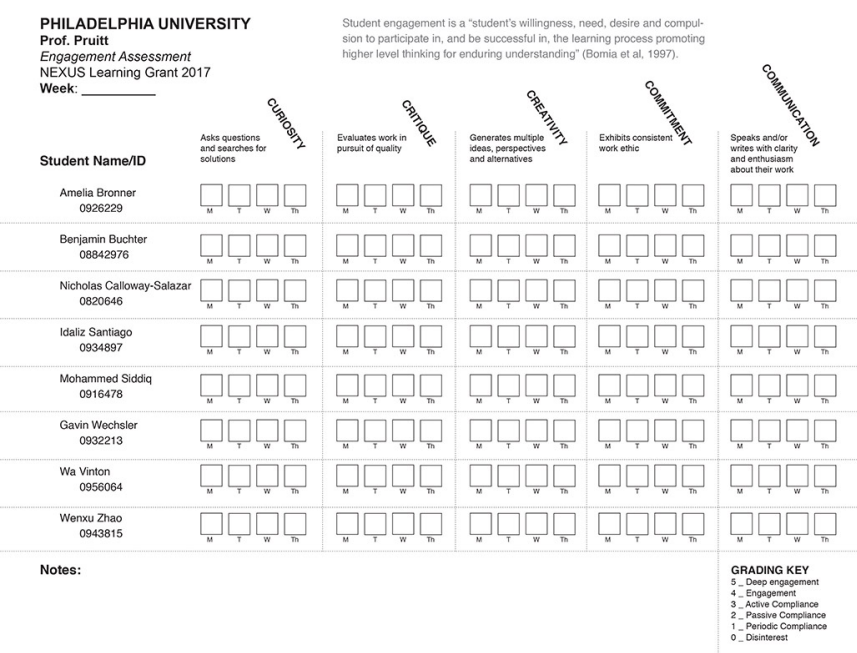

Figure 3: Studio Performance Rubric. (source: authors).

Spatially, students were asked to work in shared studio space, work in dispersed studio spaces (individual work stations spread throughout the same building), and virtually from any space of their choosing other than in studio with peers.

\begin{tabular}{|c|c|c|c|c|}
\hline & 1 & 2 & 3 & 4 \\
\hline $\begin{array}{l}\text { Shared Studio / } \\
\text { Individual Project }\end{array}$ & $\mathrm{O}$ & 0 & 0 & ( \\
\hline $\begin{array}{l}\text { Dispersed Studio / } \\
\text { Individual Project }\end{array}$ & $\mathrm{O}$ & 0 & 0 & ( \\
\hline $\begin{array}{l}\text { Shared Studio / } \\
\text { Group Project }\end{array}$ & 0 & 0 & $\mathrm{O}$ & () \\
\hline $\begin{array}{l}\text { Virtual Studio / } \\
\text { Individual Project }\end{array}$ & $\mathrm{O}$ & O & 0 & ( \\
\hline
\end{tabular}

Rate each learning environment according to your interactions with the instructor ( 1 =hard to communicate, $5=$ easy to communicate) *

\begin{tabular}{|c|c|c|c|c|}
\hline & 1 & 2 & 3 & 4 \\
\hline $\begin{array}{l}\text { Shared Studio / } \\
\text { Individual Project }\end{array}$ & 0 & 0 & 0 & ( \\
\hline $\begin{array}{l}\text { Dispersed Studio / } \\
\text { Individual Project }\end{array}$ & $\cap$ & $\bigcirc$ & 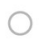 & ( ) \\
\hline $\begin{array}{l}\text { Shared Studio / } \\
\text { Group Project }\end{array}$ & 0 & $\bigcirc$ & C & ( \\
\hline $\begin{array}{l}\text { Virtual Studio / } \\
\text { Individual Project }\end{array}$ & 0 & 0 & 0 & ( \\
\hline
\end{tabular}

Figure 4: Studio Self-Assessment Survey. (source: authors).

For evaluation, three rubrics were developed that provided multiple views into the successes and/or failures of the case study course: a performance rubric, a self-assessment rubric, and a project based rubric.

The performance rubric (Figure 3) was designed for every day use by the instructor. It documented each student's performance based on perceived engagement. Engagement as a whole was broken down into five sub categories:

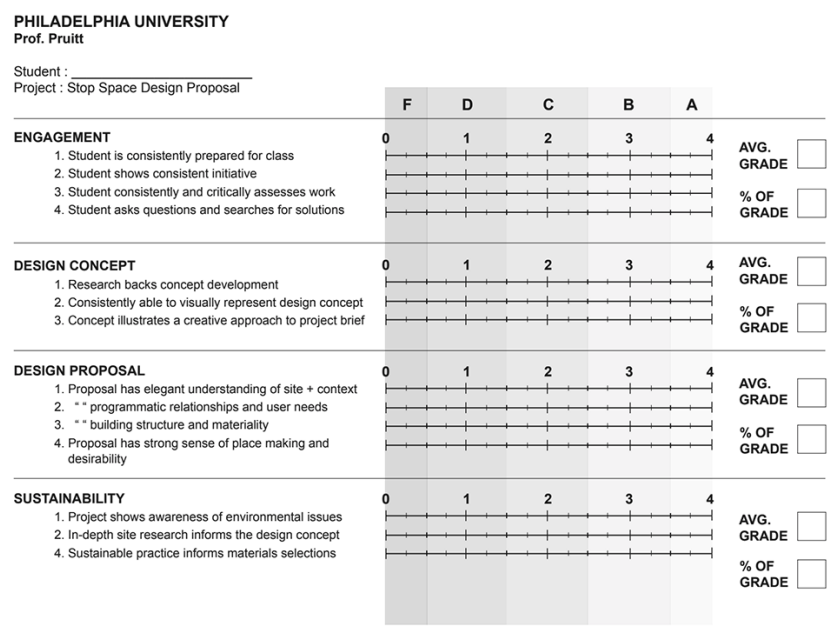

Figure 5: Studio Project Rubric. (source: authors).

- Curiosity

- Critique

- Creativity

- Commitment

- Communication

Since the course was designed to offer a variety of learning environments and project types, differences between a student's relationship to the course material was monitored and later analyzed with the daily rubrics.

The self-assessment survey rubric (Figure 4) was designed to allow students to reflect on performance and preference while also providing important feedback about the different assignment structures and their correlating successes and/ or failures.

The project rubric (Figure 5) was executed at the end of every project to evaluate the success of the project. It was written such that a student's temperament did not contribute to the project grade. For example, in rubrics past, the quality of a verbal presentation would be included as a line within the grading rubric, which could be considered advantageous to an extrovert but did not necessarily indicate a stronger or more complete design proposal. Our project based rubric attempted to remove all influences temperament may have over a project's evaluation.

The data gathered in the three rubrics was central to the overall assessment of the course.

\section{EQUITABLE COURSE OUTLINE}

Given that the test course was held during a summer session, it met four mornings a week for four hours each session for a total of six weeks. There were seven students in the course, 
most of which were placed as a result of poor academic standing or as incoming international Master's candidates. The course was broken down into the following structure:

Week 1/Project 1: Mechanistic Drawing Exercise Individual Project / Shared Studio Space

Students were asked to engage in day-long abstract drawing exercises. Each exercise built upon the work from the prior day, always yielding an unpredictable result. Students worked in a traditional studio environment, with individual workstations spread around one, shared room. Students were asked to publicly present their work to their peers each morning, after which the instructor met with each student one-on-one during semi-public desk critiques.

Week 2 / Project 2: Site Analysis and Interpretive Model Group project / Shared Studio Space

Students worked as a group to visit a site, gather data, analyze the data, design a system of notation and construct an interpretive model of the site. They worked in a traditional studio environment, with individual workstations spread around one, shared room. Students worked together in an open, active environment while the instructor facilitated group discussion and project progress.

Week 3 / Project 3: Stop_Space Individual Project / Shared Studio Space

Students were asked to develop individual design proposals for a $100 \mathrm{sq} f \mathrm{ft}$ space suitable for stopping and resting along an active recreational path. Students worked in a traditional studio environment, with individual workstations spread around one, shared room. The instructor met with each student oneon-one during semi-public desk critiques.

Week 4 / Project 4: Dwelling Research + Analysis Individual Project / Virtual Studio Space

Students were assigned a contemporary dwelling to research, diagram, interpret and present. Students were asked to select their ideal workspace as long as it was not in studio with their peers. Using the software ZOOM, students connected to a virtual meeting and the instructor began the day with a slide-based lecture. Then, each student received an individual critique from instructor in separate virtual meetings.

Weeks 5+6/Project 5: Dwelling Addition _A Studio Individual Project / Dispersed Studio Space

Students were assigned a "craft" and asked to design an addition to their contemporary dwelling that served as a studio. This was an individual project, however the students workstations were spread out within the building. This offered privacy from their peers while maintaining in-person, one-on-one contact with the instructor.

\section{STUDENT TEMPERAMENT ASSESSMENT}

Six of the seven students completed the temperament assessment at the end of the course, thus limiting our data set to six students over five weeks (the last week was not documented due to the nature of final design project work). For the purposes of this paper, students will be referred to as 1-6. The following is a summary of each student's answers to the following questions:

1. Where do you most identify on the temperament spectrum?

- always introverted

- somewhat introverted

- an even mix of introverted and extroverted

- $\quad$ somewhat extroverted

- always extroverted

2. Do you prefer group or individual projects?

3. Do you prefer to work in active or quiet environments?

Student 1:

Somewhat introverted

Individual Projects

Quiet Environments

Student 2:

Somewhat introverted

Individual Projects

Quiet Environments

Student 3:

Always Extroverted

Individual Projects

Active Environments

Student 4:

An even mix of introverted and extroverted

Individual Projects

Active Environments

Student 5:

Always Introverted

Individual Projects

Quiet Environments

Student 6:

Somewhat Introverted

Group Projects

Active Environments 
Teacher Measured Organized by Project

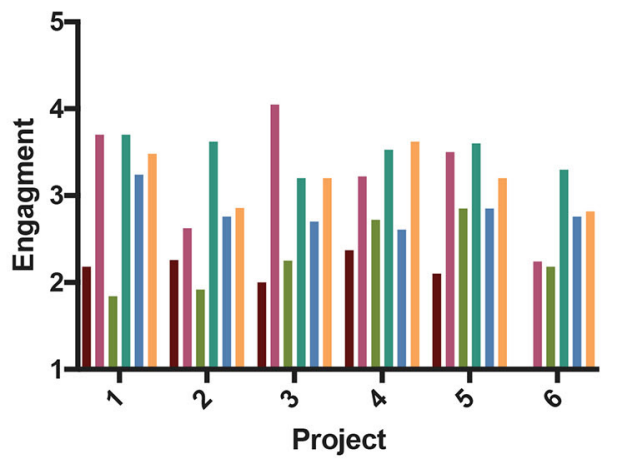

Teacher Measured Organized Student

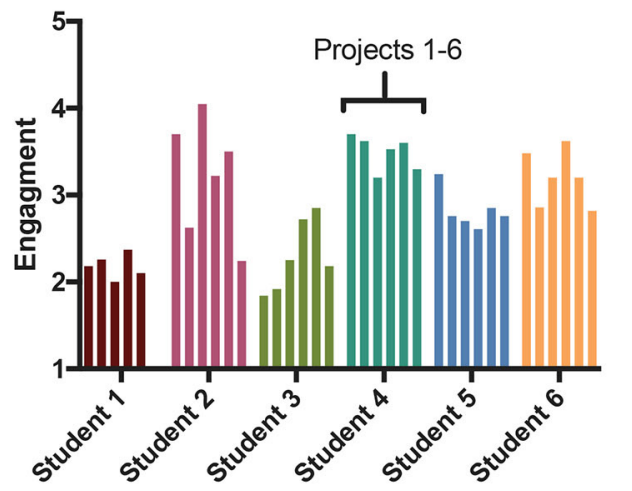

Student Measured Organized by Project

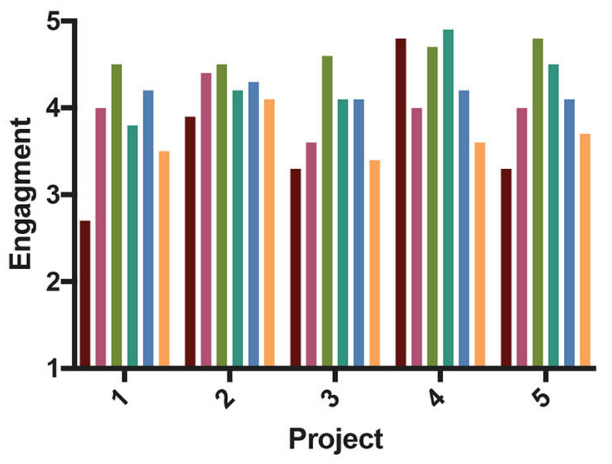

Student Measured

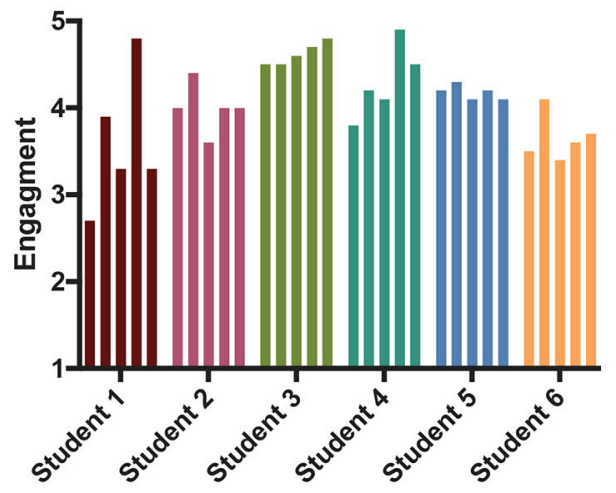

Figure 7: Studio Final Engagement Charts (source: authors)..
By random chance, the students represented a fairly even spread for temperament, as well as pedagogical and spatial preference. Since each project was designed to appeal to different temperaments, and pedagogical and spatial preferences, we would expect to see varied levels of engagement from each student throughout the course.

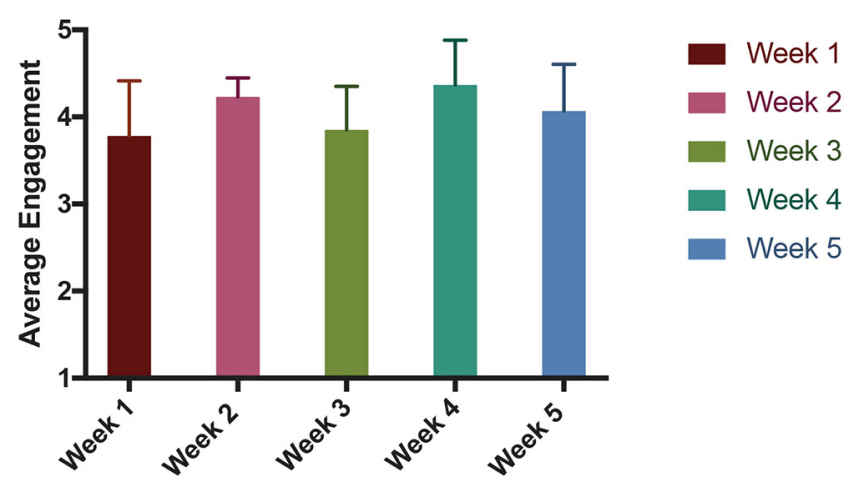

\section{FINDINGS}

Our objective was to analyze the combined performance rubric, self-assessment rubric and the project rubric to learn if a particular pedagogical and environmental combination achieved an equitable learning environment.

The following graphs represent the data according to different filters:

- Instructor perceived levels of total engagement (the average of the 5 C's detailed in the Studio Metrics) per project and per student.

- Student Perceived levels of total engagement per project and per student.

- Average of total engagement throughout the course.

The graphs illustrate that the student-measured levels of engagement were generally inflated far above the instructormeasured levels, and also did not vary project to project as drastically as the instructor's observations. As a result, one may conclude that using the student-measured data is less accurate in depicting the actual level of engagement.

The instructor-measured levels of engagement, however, indicate a unique result in Weeks 2 and 4 of the course. Week 4 , the virtual instruction week, receives the highest levels of engagement from the introverted students. Week 2, the group project, indicates lower levels of engagement from the introverted students.

\section{CONCLUSION}

The above analysis follows our hypothesis that students with introverted temperaments respond to learning environments 
that are less open, less active and less public. Much more analysis of the data needs to take place to make grand proclamations, however the results thus far make the case that courses should be designed to accommodate a variety of temperaments by varying both pedagogical and spatial environments. We look forward to conducting further research in this field, ideally with more students who are established "in sequence" and enrolled in a semester long course.

\section{ENDNOTES}

1 Krajcik \& Blumfeld; “Project Based Learning." From Sawyer, Ed.; The Cambridge Handbook of the Learning Sciences. (Cambridge, MA: Cambridge University Press. 2006) Chapter 19.

2 Brown, Tim; Change by Design: How Design Thinking Transforms Organizations and Inspires Innovation. (New York: Harper Business. 2009)

3 Krajcik \& Blumfeld, 370

4 Of a side note are the discussions on educationally engaging younger generations. Christy Prices's “The Five R's of Engaging Millennial Students" (from Lilly Teaching Conference and multiple on-line articles) echoes qualities of successful projects in consideration of means to connect with younger students. She posits that characteristics such as "Research-based Methods, Clear Relevance, Clear Rationale, Relaxed Environment \& Good Rapport" are class qualities which lead to successful student engagement.

5 Jonassen, David; “Designing Constructivist Learning Environments.” Reigeluth (Ed.); Instructional Theories and Models. Second Edition. (Mahwah, NJ: Lawrence. 1998)

6 Krajcik \& Blumfeld, 372.

7 Sennett, Richard; "Exploring our Neglect of Craft and Love of Money." RSA Journal, Spring Issue 2008.

8 Krajcik \& Blumfeld; $p$ 371. Summarizing Toulmin; Human Understanding (Princeton: Princeton University Press. 1972)

9 Cain, Susan; Quiet: The Power of Introverts in a World That Can't Stop Talking (New York: Broadway Books. 2013).

10 Cain, Susan; Quiet

11 At Thomas Jefferson University this institutional program is called Nexus Learning. 